\title{
ENDOSCOPIC ENDONASAL TRANS-SPHENOIDAL SURGERY: OUR EXPERIENCE OF 40 PITUITARY ADENOMAS TREATED AT A TERTIARY CENTRE
}

\author{
Pankaj Gupta1, Jitendra Singh ${ }^{2}$, Arvind Sharma ${ }^{3}$, Shameer Deen ${ }^{4}$, Surbhi Tyagi ${ }^{5}$ Akansha Tanwar 6 \\ ${ }_{1}^{1}$ Professor and HOD, Department of Neurosurgery, Mahatma Gandhi Medical College \& Hospital. \\ ${ }^{2}$ Assistant Professor, Department of Neurosurgery, Mahatma Gandhi Medical College \& Hospital. \\ ${ }^{3}$ Assistant Professor, Department of Neurosurgery, Mahatma Gandhi Medical College \& Hospital. \\ ${ }^{4} P G$ Resident, Department of General Surgery, Mahatma Gandhi Medical College \& Hospital. \\ ${ }_{5}^{5}$ Assistant Professor, Department of Pathology, Mahatma Gandhi Medical College \& Hospital. \\ ${ }^{6} J$ uniorResident, Department of Neurosurgery, Mahatma Gandhi Medical College \& Hospital.
}

\begin{abstract}
Introduction of Endoscope has revolutionized the surgical management of Pituitary tumors. Endoscopic endonasal approach has now become the most acceptable and routinely done procedure. In our tertiary center, we have analysed the data of 40 patients, who underwent endoscopic endonasal surgery over a period of one year. Clinical parameters, tumor excision, endocrinological status, complication rates were retrospectively analysed. One month follow up with repeat MRI and hormonal status was compared with pre-operative findings. There were 15 functioning and 25 non-functioning pituitary adenomas. There were 6 prolactinomas, 4 acromegaly, 4 Cushing and 1 FSH secreting pituitary adenoma. 25 were non-functioning adenomas. There was one microadenoma with Cushing syndrome. Subtotal excision was done in $76 \%$ of non-functioning and $66 \%$ of functioning adenomas. The remission rates were $80 \%$ in non-functional and almost $75 \%$ in functional pituitary adenoma. In our series, endoscopic approach proved to be less invasive, excellent tumors removal rate and better post-operative results. The complications were also less and comparable to other conventional methods. But it has steep learning curve and needs technical skills.
\end{abstract}

\section{KEYWORDS}

Endoscopic Endonasal Trans-sphenoid Surgery, Pituitary Adenoma, Diabetes Insipidus.

HOW TO CITE THIS ARTICLE: Gupta P, Singh J, Sharma A, et al. "Endoscopic endonasal trans-sphenoidal surgery: our experience of 40 pituitary adenomas treated at a tertiary centre." Journal of Evolution of Medical and Dental Sciences 2015; Vol. 4, Issue 105, December 31; Page: 17074-17077, DOI: 10.14260/jemds/2015/2587

\section{INTRODUCTION}

Pituitary surgery has evolved over the years and with the introduction of endoscope there was the drift from the conventional microscopic to less invasive endoscopic end nasal technique. $[1,2,3,4,5]$ But this technique demands for precise anatomical knowledge and technical skills. Though we have been doing endoscopic surgery for quite some time but this study has been done since last 1 year in our tertiary center with all modern instrumentation and neuro-navigation.

\section{STUDY DESIGN}

The study has been done on 40 patients between November 2014 to October 2015 which were operated in Mahatma Gandhi Medical College and Hospital, Jaipur (INDIA). We retrospectively analysed the clinical and surgical data of all the patients. Pure pituitary lesions including one craniopharyngioma with synchronous adenoma and one mucocele were included in the study. Other sellar and suprasellar lesions including pure craniopharyngioma were excluded from the study.

Financial or Other, Competing Interest: None.

Submission 30-11-2015, Peer Review 01-12-2015,

Acceptance 26-12-2015, Published 31-12-2015.

Corresponding Author:

Dr. Pankaj Gupta,

Department of Neurosurgery,

Mahatma Gandhi Medical College and Hospital,

RIICO, Sitapura,

Jaipur,

Rajasthan.

E-mail: gupta.pankaj297@gmail.com

DOI:10.14260/jemds/2015/2587
All the tumors were sent for immunohistochemical analysis. Endocrinological tests were performed at our center, which included Prolactin, IGF1, GH level with oral GTT and early morning cortisol value along with FT3, FT4, TSH and FSH and LH were done in almost all patients. Follow-up CT scan was done on $2^{\text {nd }}$ postop day and at one month interval.

\section{RADIOLOGICAL INVESTIGATION}

All the patients had undergone Magnetic Resonance Imaging (MRI) with contrast.

CT PNS was also done in almost every patient for anatomy of sella, sphenoid sinus, septum and follow up MRI was done at 1-month interval.

\section{SURGICAL TECHNIQUE}

All the patients were operated by the same team of neurosurgeons under GA. Patients were placed in supine position with the head slightly flexed and tilted towards operating surgeon's side. The operating surgeon was positioned on right side along with first assistant. No ENT surgeon was required in any surgery. A telescope was placed in right nostril along with suction and left nostril was used for other instruments at different stages of the procedure. All procedures were performed by a bilateral approach with a zero degree rigid telescope was for nasal and sphenoid phase and a thirty degree telescope used during tumor removal from the parasellar and supraseller regions. Intraoperative image guidance (Neuro-navigation) proved to be a useful tool in variable sphenoid anatomy. Adrenaline 1:10,000 soaked patties were placed in both the nostrils prior to painting and draping to decongest the nasal mucosa. 
The telescope was navigated into the right nasal cavity, the choana reached and approx. $1.5 \mathrm{~cm}$ above choana the sphenoid ostium was identified. We usually lateralized the middle turbinate but in the majority of cases with a bulky middle turbinate, deviated nasal septum towards right side and in acromegaly patients with hypertrophied nasal mucosa, middle turbinectomy was performed to accommodate the telescope and acquire a better view. The sphenoid ostium was widened and then septum perforated and the opposite side ostium was reached and posterior nasal septectomy done. A microdebrider was used to excise soft tissues followed by Kerrison rongeurs and drill to widen the anterior phase of the sphenoid sinus.

A part of the rostrum was left in situ to indicate mid line. A Diamond burr was used to drill the sellar floor and intersphenoid septas and dura was exposed, which was incised in $U$ shaped or cruciate fashion with knife and tumor was decompressed with zero degree telescope. Thirty degree and forty-five degree telescopes were used to inspect the cavity for any residual tumor. Sellar floor reconstruction was done when there was arachnoid tear using fat, fibrin blue and gel-foam. Vascularized mucosal flap was rarely required.

\section{TUMORS CONTROL}

The aim of surgery was to remove as much as tumor as possible without damaging the normal pituitary gland or arachnoid. Criteria for disease control were total tumor removal in non-functioning and hormonal control in functioning pituitary tumors. The success of surgery was based on surgeon's intraoperative vision and MRI with contrast done 1 month after surgery.

\section{RESULTS}

Over one year period 40 patients underwent endoscopic end nasal surgery. Male were 14 (35\%) and females 16 (40\%) of total patients. The mean age of patients was 40.51 years with range between 24-76 years. According to size 39 were macroadenomas (97.5\%) and only one (2.5\%) microadenoma. Localized perforation of sellar was seen in $16(40 \%)$ patients and diffuse perforation seen in $22(55 \%)$ patients and 2 (2\%) patients had normal sella. Cystic component was found in 9 $(22.5 \%)$ patients and intra-tumoral bleed in $4(10 \%)$ patients. Headache and visual complaints were present in almost 34 (85\%) patients, 2 (5\%) patients had Cushing syndrome, one patient presented with amenorrhoea and other 2 with coarsening of features (Acromegaly). Three patients had history of sudden decrease in vision (Apoplexy) of which 2 improved gradually. Two patients had diplopia along with visual complaints and one patient of Cushing had altered consciousness which improved following surgery.

Among all patients 4 patients had significant tumor left due to significant suprasellar and parasellar extension and other 7 patients had less than subtotal excision (Less than $80 \%$ tumor removal). Among the 25 non-functional tumors 19 (76\%) had subtotal excision and among functioning 6 (24\%) had subtotal excision. All patients except one recovered well after surgery. One patient who expired was hypothyroid and there was arachnoid tear and CSF leak during surgery. Lumbar drain was placed immediately following surgery. Patient had severe headache on $3^{\text {rd }}$ postop day and became unconscious and expired on $13^{\text {th }}$ postop day.
Meningitis was suspected to be the culprit. Out of rest of the, six patients had transient diabetes insipidus and required intranasal/oral Vasopressin spray and all of them improved. No patient in our study developed permanent diabetes insipidus.

One patient presented with delayed nasal bleed after 15 days of surgery and was re-explored and the bleeder from SER dura was coagulated. Among all patients the mean hospital stay was 5 days. The patients who required longer hospital stay were one with deep vein thrombosis, one with CSF leak, diabetes insipidus and one patient of Cushing's disease with altered sensorium, all were managed conservatively. Among all patients only two had undergone combined endoscopic and transcranial approach. Out of 4 patients of Cushing's, three underwent surgery and had complete resolution of symptoms and normalized cortisol levels and whereas one patient developed panhypopituitarism and was conservatively managed and recovered gradually. Among 6 prolactinomas, 5 improved clinically and chemically and only one patient required post-operative bromocriptine therapy. All 4 patients of acromegaly had significant improvement in hormonal and clinical symptoms.

\section{DISCUSSION}

Microsurgical trans-sphenoid surgery for pituitary adenomas has been the standard treatment for decades.[1,2,3,4,5] Among various techniques, Sublabial trans-septal and trans-nasal trans-septal approaches are the most commonly used. $[3,4,5$, Since the endoscope became popular in paranasal sinus surgery. ${ }^{[6,7]}$ it has increased the interest of neurosurgeons for its use in trans-sphenoid surgeries. In late nineties, a large series of endoscopic pituitary surgeries by Jho and Carrau. ${ }^{8,9}$ and Cappabeenca et al. ${ }^{10}$ increased the sudden interest in this technique worldwide. Jankowski et al. ${ }^{11}$ first reported endoscopic endonasal resection of pituitary adenoma in 3 patients. A panoramic view inside the surgical area, close up of anatomy and an improved working angle were advantages of the endoscopic procedure. There were less nasal injuries due to speculum and decreased morbidity. ${ }^{22,13,14,15}$ The results of microscopic and endoscopic surgery for tumor resection and hormonal control is extensively compared.[14,15] In our series most of the tumors were macroadenoma with mean tumor size $26 \pm 10.2 \mathrm{~mm}$ with suprasellar and parasellar extension, which was larger than most of the series. ${ }^{15,16}$ This explains why our results were slightly inferior.

Dehdashti et al. reports gross total excision in $88 \%$ patients. Endoscopic surgical control of non-functioning adenomas varies from $62 \%-93 \%$. According to Tabee et al.[16] there is a 3 fold decrease in tumor removal with every $1 \mathrm{~cm}$ increase in the tumor size $(\mathrm{P}=0.047)$. Our disease control results in functioning pituitary tumors $(75 \%)$ are similar to previously presented series. ${ }^{14,15,16,17,18,19,20}$ Nasal complications in our series were less as compared to others. Transient diabetes insipidus was higher but there was no permanent diabetes insipidus or Syndrome of Inappropriate Antidiuretic Hormone secretion (SIADH). ${ }^{15,16,20,21}$ CSF leak and meningitis were also comparable.16,22,23 We had a higher mortality rate but death was not directly related to surgical procedure. 


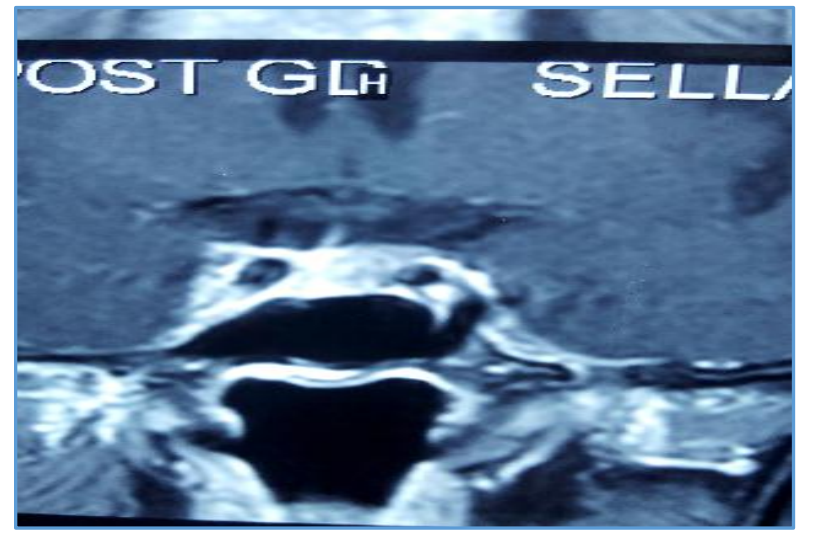

Postop Image of Pituitary Tumor

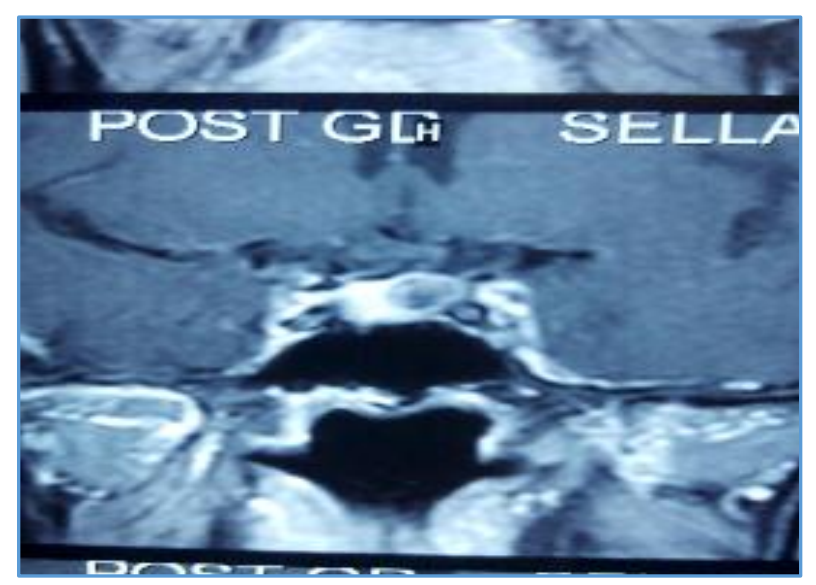

Preop Image of Pituitary Tumor

\section{CONCLUSION}

Endoscopic approach is minimally invasive and effective treatment for pituitary adenomas with less complications and a decreased hospital stay. Endoscope provides the view which cannot be obtained in tubular vision of operating microscope especially in parasellar and suprasellar extensions. Although the results of endoscopy and microscopy are comparable, there is a definitive inclination towards endoscopic surgery.

\section{REFERENCES}

1. Adams CBT, Burke CW: Current modes of treatment of pituitary tumors. Br J Neurosurg 7:123127C.

2. Black PMCL, Zervas NT, Candia G: Incidence and management of complications of trans-sphenoidal operation for pituitary adenomas. Neurosurgery 20:920924,1987.

3. Guiot A: Trans-sphenoidal approach in surgical treatment of pituitary adenomas: General principles and indications in nonfunctioning adenoma, in Kohler PO, Ross GT (eds): Diagnosis and Treatment of Pituitary Tumors. Amsterdam: Excerpta Medica, 1973, pp 159178.

4. Trans-sphenoidal approach to the pituitary gland, in Wilkins RH, Rengachary SS (eds): Neurosurgery. New York: McGraw-Hill, 1985, Vol 1, pp 889-899.

5. Hardy J: Transphenoidal microsurgery of the normal and pathological pituitary. Clin Neurosurg 16:185217,1969.

6. Stammberger H: Endoscopic endonasal surgery--concepts in treatment of recurring rhinosinusitis. Part II. Surgical technique. Otolaryngol Head Neck Surg 94:147-156, 1986.

7. Zervas NT: Surgical results in pituitary adenomas: results of international survey, in Black PM, Zervas NT, Ridway EC
Jr, et al. (eds): Secretory Tumors of the Pituitary Gland. New York: Raven Press, 377-384.

8. Jho H, Carrau R (1996). Endoscopy assisted transsphenoidal surgery for pituitary adenoma. Acta Neurochir (Wien) 138:1414-1422.

9. Jho H, Carrau R (1997). Endoscopic endonasal transsphenoidal surgery: experience with fifty patients. J Neurosurg 87:44-51, Cappabianca P, Alfieri A, de Divitiis E (1998). Endoscopic endonasal trans-sphenoidal approach to the sella: towards Functional Endoscopic Pituitary Surgery (FEPS). Minim Invasive Neurosurg 41:66-73.

10. Hadad G, Bassagasteguy L, Carrau RL, Mataza JC, Kassam A, Snyderman $\mathrm{CH}$, et al. (2006). A novel reconstructive technique following endoscopic expanded endonasal approaches: vascular pedicle nasoseptal flap. Laryngoscope 116:1881-1888.

11. Jho HD, Carrau RL, Ko Y, et al. (1997). Endoscopic pituitary surgery: an early experience. Surg Neurol 7:213-223.

12. Cappabianca P, Cavallo LM, de Divitiis E (2004). Endoscopic endonasal transsphenoidal surgery. Neurosurgery 55:933-940.

13. Dehdashti AR, Ganna A, Karabatsou K, (2008). Pure endoscopic endonasal approach for pituitary adenomas: early surgical results in 200 patients and comparison with previous microsurgical series. Neurosurgery 62:10061017.

14. Koren I, Hadar T, Rappaport ZH, et al. (1999). Endoscopic transnasal trans-sphenoidal microsurgery versus the sublabial approach for the treatment of pituitary tumors: endonasal complications. Laryngoscope 109:1838-1840.

15. Cho D-Y, Liau W-R (2002). Comparison of endonasal endoscopic surgery and sublabial microsurgery for prolactinomas. Surg Neurol 58:371-376.

16. Tabaee A, Anand VK, Barro'n Y, Hiltzik DH, Brown SM, Kacker A, et al. (2008). Predictors of short-term outcomes following endoscopic pituitary surgery. Clin Neurol Neurosurg 2:119-122.

17. Frank G, Pasquini E, Farneti G, Mazzatenta D, Sciarretta V, Grasso V, et al. (2006). The endoscopic versus the traditional approach in pituitary surgery. Neuroendocrinology 83:240-248.

18. Jain AK, Gupta AK, Pathak A, et al. (2008). Endonasal transsphenoidal pituitary surgery: is tumor volume a key factor in determining outcome? Am J Otolaryngol 29(1):48-50.

19. Jho HD, (2001). Endoscopic trans-sphenoidal surgery. J Neurooncol 54:187-195.

20. Kabil MS, Eby JB, Shahinian HK, (2005). Fully endoscopic endonasal versus trans-septal trans-sphenoidal pituitary surgery. Minim Invasive Neurosurg 48:348-354.

21. Shen CC, Wang YC, Hua WS, et al. (2000). Endoscopic endonasal transsphenoidal surgery for pituitary tumors. Chin Med J Taipei 63:301-310.

22. Cappabianca P, Cavallo LM, Colao A, et al. (2006). Surgical complications associated with the endoscopic endonasal trans-sphenoidal approach for pituitary adenomas. J Neurosurg 97:293-298.

23. De Divitiis E, Cappabianca P, Cavallo M, (2003). Endoscopic endonasal trans-sphenoidal approach to the sellar region. In: De Divitiis E, Cappabianca P (eds) Endoscopic Endonasal Transsphenoidal Surgery. Springer. Wien, pp 91-130. 


\begin{tabular}{|c|c|c|}
\hline Adenoma Characteristics & Number & \% \\
\hline Total Patients & 40 & 100 \\
\hline Non-Functioning & 25 & 62.5 \\
\hline Functioning & 15 & 37.5 \\
\hline GH Secreting & 4 & 10 \\
\hline Prolactinomas & 6 & 15 \\
\hline ACTH Secreting & 4 & 10 \\
\hline FSH/LH Secreting & 1 & 2.5 \\
\hline TSH Secreting & 0 & 0 \\
\hline \multicolumn{2}{|c|}{ Table 1: Characteristics of Tumor } \\
\hline
\end{tabular}

\begin{tabular}{|c|c|c|}
\hline Surgery & Number & Percentage \\
\hline Non-Functioning & 25 & 62.5 \\
\hline Subtotal & 19 & 76 \\
\hline Partial Resection & 6 & 24 \\
\hline \multicolumn{2}{|c|}{} \\
\hline Functioning & 15 & 37.5 \\
\hline Subtotal & 10 & 66.67 \\
\hline Partial Resection & 5 & 33.33 \\
\hline \multicolumn{2}{|c|}{ Table 4: Surgical Aspects } \\
\hline
\end{tabular}

\begin{tabular}{|c|c|c|}
\hline Tumor Characteristics & Number & Percentage \\
\hline Microadenoma & 1 & 2.5 \\
\hline Macroadenoma & 39 & 97.5 \\
\hline $\begin{array}{c}\text { Suprasellar and Parasellar } \\
\text { Extension }\end{array}$ & 35 & 87.5 \\
\hline $\begin{array}{c}\text { Localized Perforation of } \\
\text { Sella }\end{array}$ & 16 & 40 \\
\hline Diffuse perforation of Sella & 22 & 55 \\
\hline Normal Sella & 2 & 5 \\
\hline Cystic Component & 9 & 22.5 \\
\hline Tumoral Bleed & 4 & 10 \\
\hline \multicolumn{2}{|l}{ Table 2: Tumor Characteristics } \\
\hline
\end{tabular}

\begin{tabular}{|c|c|c|}
\hline $\begin{array}{c}\text { Presenting } \\
\text { Symptoms }\end{array}$ & Number & Percentage \\
\hline $\begin{array}{c}\text { Headache and } \\
\text { Visual Symptoms }\end{array}$ & 34 & 85 \\
\hline \multicolumn{2}{|c|}{ Hormonal Symptoms } \\
\hline Cushing Syndrome & 2 & 5 \\
\hline Acromegaly & 2 & 5 \\
\hline Amenorrhoea & 1 & 2.5 \\
\hline Diplopia & 2 & 5 \\
\hline Altered Sensorium & 1 & 2.5 \\
\hline $\begin{array}{c}\text { Sudden Visual Loss } \\
\text { (Apoplexy) }\end{array}$ & 3 & 7.5 \\
\hline \multicolumn{2}{|c|}{ Table 3: Clinical Symptoms } \\
\hline
\end{tabular}

\begin{tabular}{|c|c|c|}
\hline Complication & Number & Percentage \\
\hline SIADH & 0 & 0 \\
\hline Transient & 6 & 15 \\
\hline Permanent & 0 & 0 \\
\hline Post Op Bleed & 1 & 2.5 \\
\hline CSF Leak & 2 & 5 \\
\hline Meningitis & 1 & 2.5 \\
\hline $\begin{array}{l}\text { Death (Following CSF } \\
\text { leak and meningitis) }\end{array}$ & 1 & 2.5 \\
\hline Seizures & 0 & 0 \\
\hline ICA Injury & 0 & 0 \\
\hline Panhypopituitarism & 1 & 2.5 \\
\hline Deep Vein Thrombosis & 1 & 2.5 \\
\hline \multicolumn{3}{|c|}{ Table 5: Complications } \\
\hline
\end{tabular}

